\title{
Editorial
}

\section{Leading transition while maintaining tradition}

\author{
James T. RutKa, M.D., Ph.D., F.R.C.S.C.
}

\author{
Division of Neurosurgery, Department of Surgery, University of \\ Toronto, Ontario, Canada
}

I am deeply honored to be appointed as the new Editor-in-Chief (EIC) of the Journal of Neurosurgery $(J N S)$. I follow Dr. John Jane Sr., who has served admirably and tirelessly in this role since October 1992, and has implemented numerous transformative changes within the Journal of Neurosurgery Publishing Group (JNSPG) (Fig. 1). As such, the task for me is somewhat daunting; however, I view this task as a tremendous opportunity at a time when the standard operating procedures for publications for associations, such as the American Association of Neurological Surgeons (AANS), are being rewritten, in part, by shifts from print to online publishing. At a time of transition, such as this, it is wise to review salient aspects of the history of the JNS as we prepare to chart a new course for our future.

Since its inception in 1944 there have been 6 previous EICs of the JNS (Table 1), all of whom have left indelible marks on the progress and stature of the journal. In addition, we should also remember the insightful and deliberative force of Dr. John F. Fulton, who, in the spring of 1943, in response to a request by Dr. Alfonso Asenjo in Santiago, Chile, worked with the officers of the Harvey Cushing Society (now AANS) to establish the first specialty-specific and international journal devoted to neurosurgery. In the words of Dr. R. Glen Spurling, a major participant in the US military effort during World War II, Dr. Fulton "fathered the JNS." The first issue of the journal was published in January 1944, and the lead article was written by Dr. Gilbert Horrax on the many contributions of Harvey Cushing to the science and practice of neurosurgery throughout his career. ${ }^{4}$ There were initially 5 members appointed to the Editorial Board. Issues were published bimonthly until 1962, at which time it was necessary to increase the number of issues to 12 per year to accommodate the ever-increasing number of accepted submissions.

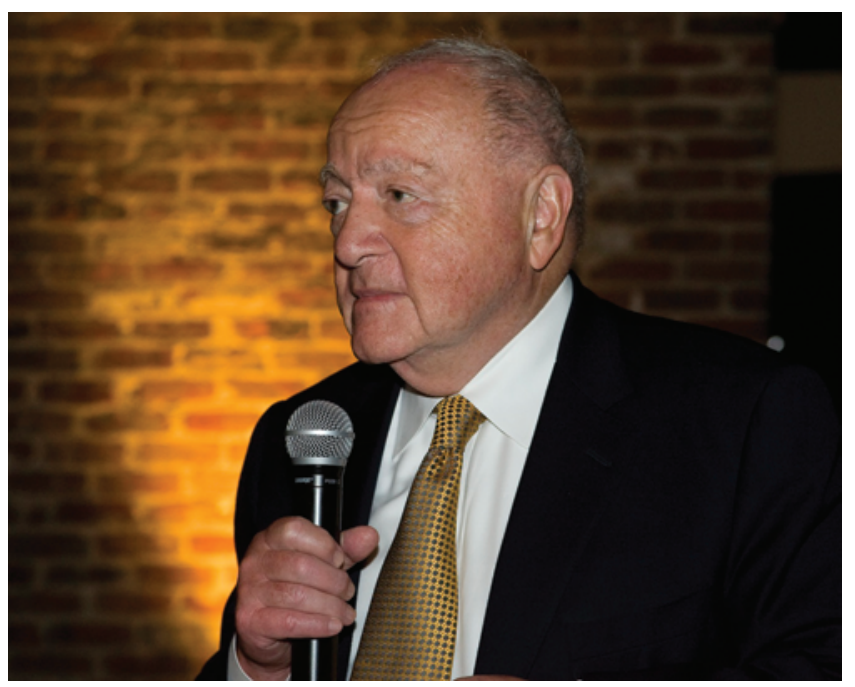

FIG. 1. Dr. John A. Jane Sr., Editor-in-Chief, JNSPG, 1992-2013. Some of his many contributions to the JNS include the creation and establishment of Neurosurgical Focus, the JNS: Pediatrics, and the JNS: Spine; expansion of the Editorial Boards for each of the 3 print journals; acceptance to online publication within 30 days policy; the development of topic-oriented issues for the JNS; and the development of a highly efficient and professional self-publishing office in Charlottesville, Virginia. Photo, AANS annual meeting, Denver, 2011.

From its first issue, the JNS has been maintained as an international journal accepting neurosurgical submissions from around the world. ${ }^{1,8}$ The same holds true to this day, with authors from over 60 countries submitting their best work for peer review in 2012. In this era of bibliometrics, we can indeed be proud of the JNS, which, from 2011 data, has a 5-year Impact Factor (IF) of 3.088, and total citations of 28,800 , which is more than any other neurosurgical journal. The proliferation of neurosurgical centers throughout the world and the widespread accessibility of scientific and clinical data have led to an exponential rise in the number of submissions and, consequently, the number of published pages in the JNS over the past 50 years. Whereas in 1963 there were 165 individual papers and 1111 pages of text published in the $J N S,{ }^{1}$ in 2012 there were 1208 accepted manuscripts from a total of 3604 submissions, and a near 5-fold increase in pages printed at 5106 pages. Obviously, to accommodate such an incredible increase in volume of submissions and 
TABLE 1: Editors-in-Chief of the Journal of Neurosurgery

\begin{tabular}{lc}
\hline \multicolumn{1}{c}{ Editor-in-Chief } & Years of Service \\
\hline Louise Eisenhardt, M.D. & $1944-1965$ \\
Henry Heyl, M.D. & $1965-1975$ \\
Henry Schwartz, M.D. & $1975-1985$ \\
William Collins Jr., M.D. & $1985-1990$ \\
Thoralf Sundt Jr., M.D. & $1990-1992$ \\
John A. Jane Sr., M.D., Ph.D. & $1992-2013$ \\
\hline
\end{tabular}

published works, some important innovations have transpired under Dr. Jane's leadership as EIC, and I should like to comment upon these now.

With the advent of digital publishing technologies in the 1990s, Dr. Jane quickly recognized the importance of e-communications and inaugurated Neurosurgical Focus in 1997 under the direction of Dr. Martin Weiss. Neurosurgical Focus has been an increasingly successful e-journal and is highly sought-after by a worldwide audience for its publication of timely and topic-oriented issues. ${ }^{6}$ From an analysis of 2011 neurosurgical journal impact data, Neurosurgical Focus has a remarkable IF of 2.867 .

Responding to subspecialty sections who were potentially threatening to withdraw their support and secede from organized neurosurgery, Dr. Jane wisely created and established the JNS: Spine in 1999, and in 2004 the JNS: Pediatrics, which became the official journal of the American Society of Pediatric Neurosurgeons (ASPN). In breaking with the tradition stating that all Editorial Board members be neurosurgeons, Dr. Jane sanctioned the appointment of several prominent orthopedic spine surgeons to the Editorial Board to attract the very best in clinical and basic science spine research to the JNS: Spine. Dr. Jane has also allowed for the Executive Committee of the ASPN to participate in the selection of new Editorial Board members for the JNS: Pediatrics.

While a small number of Editorial Board members (5 to be precise*) could be in charge of reviewing all submissions to the JNS in its early days when there were only 6-12 issues per year, clearly this became untenable with the increase in volume of submissions and the production of 48 issues per year, consisting of 12 each for the $J N S$, the JNS: Spine, the JNS: Pediatrics, and Neurosurgical Focus. Accordingly, Dr. Jane continued the gradual increase in the number of Editorial Board members that was started by Dr. Collins in the 1980s. ${ }^{5-7}$ There are now 34 members across the 3 Editorial Boards, each of whom reviews over 300 manuscripts per year. If that workload is not enough to impress you, then please consider that the Chairs of the Editorial Boards may review more than twice that number of manuscripts through the course of a year. As such, I am personally in awe of the talent of the current Editorial Board members, and their devotion to

\footnotetext{
* There were 5 Editorial Board members from 1944 to 1959,6 from 1961 to 1963 , and then 5 from 1963 to 1984 . Further expansion of the Editorial Board gradually occurred from this time forward.
}

the mission of the JNS, which is to advance the practice of neurosurgery worldwide. Other innovations that Dr. Jane has led within just the past 5 years include acceptance to online publication in 30 days and the development of topic-oriented issues for the JNS.

The JNSPG is self-published, and its offices reside in Charlottesville, Virginia, where 20 of the most capable and dedicated staff in the field work to provide the very best in manuscript and copy editing and journal production in the realm of neurosurgical publications. Since its inception, the $J N S$ has been profitable, and never has this been more true than in the past 2 years when record proceeds were returned to the AANS. The establishment of the JNSPG in Charlottesville is therefore part of Dr. Jane's great legacy as EIC, and I look forward to working with the joint Directors of Publications, Mary Beth Yeaton and Gillian Shasby, as well as Margie Shreve, who has worked with the JNSPG for 24 years and has been indispensable for Dr. Jane's efforts. I will work closely with the entire staff in Charlottesville toward our future goals.

What are my goals and vision for the JNSPG? I will strive my utmost to maintain the JNS as the journal of record in our specialty through the continued recruitment of the best Editorial Board members; by encouraging prospective authors to submit their best clinical and basic science research studies to the journal; by improving upon the IF for all 4 JNSPG journals; by expanding our Web presence and video offerings; by developing new and improved smartphone applications; by moving forward intelligently in the social media sphere; by enhancing our global outreach; and by remaining as a selfpublished journal using our increasing revenues to renew the JNS mission and to support the AANS.

There are some clouds looming on the horizon that have the potential of darkening the future of scientific publishing. ${ }^{2}$ We still do not know, for example, the fate of open-access publishing. ${ }^{2,9}$ In a recent editorial in Nature, ${ }^{3}$ a survey of over 23,000 scientists showed that many are unsure if they should publish their data in an open-access format. We still do not know how the corporate world and our industry sponsors will view and support a move from print to online advertising. And in the specialty of neurosurgery, we still do not know the inflection point between print and digital audiences. Despite this uncertainty, in the end, the future of journal publishing may be a composite of research data, references, text, and software that "interlinks with tools for analysis, annotation, visualization and citation." 3

I would like to conclude by thanking the members of the JNSPG Editorial Boards for bestowing their trust and confidence in me as their new EIC. I should also like to thank Dr. Jane for his incredible dedication and devotion to the JNS over the past 21 years. No one has worked harder than he to maintain and uphold the traditions of the journal. While a transition in leadership creates an indispensible opportunity for change that we should all embrace, it also provides time for reflection on and adherence to those traditions that Dr. Jane has unwaveringly upheld during his term as EIC, and that have served the $J N S$ so well over the past 7 decades.

(http://thejns.org/doi/abs/10.3171/2013.5.JNS13987) 


\section{Editorial}

\section{References}

1. Bucy PC: The Journal of Neurosurgery. Its origin and development. 1964. J Neurosurg 80:160-165, 1994

2. Butler D: Investigating journals: the dark side of publishing. Nature 495:433-435, 2013

3. Disciplinary action: how scientists share and reuse information is driven by technology but shaped by discipline. Nature 495:409-410, 2013

4. Horrax G: Some of Harvey Cushing's contributions to neurological surgery. J Neurosurg 1:3-22, 1944

5. Jane JA: Editorial comment. The golden anniversary celebration of the Journal. J Neurosurg 80:1-2, 1994

6. Jane JA Sr: History of the Journal of Neurosurgery, in Wilkins
RH: History of the American Association of Neurological Surgeons. Virginia Beach, VA: Donning Company Publishers, 2007, pp 58-63

7. Laws ER Jr: The binding influence of the Journal of Neurosurgery on the evolution of neurosurgery. J Neurosurg 81:317321, 1994

8. Schwartz HG: Commemorative article. History of the Journal of Neurosurgery, 1965-1980. J Neurosurg 80:939-940, 1994

9. Van Noorden R: Open access: the true cost of science publishing. Nature 495:426-429, 2013

Please include this information when citing this paper: published online June 4, 2013; DOI: 10.3171/2013.5.JNS13987. 